\title{
Duty of Care and the Overall Impact of Infectious Diseases
}

\author{
Bara $\mathrm{S}^{1 *}$ and Bara $\mathrm{J}^{2}$ \\ ${ }^{1}$ Faculty of Dental Medicine, University of Tirana, Albania \\ ${ }^{2}$ Department of Criminal law, Faculty of Law, University of Tirana, Albania
}

*Corresponding author: Silvana Bara, Faculty of Dental Medicine, University of Tirana, Albania, Email: silvana.bara@umed.edu.al

\section{Mini Review \\ Volume 3 Issue 4}

Received Date: October 12, 2020

Published Date: November 11, 2020

DOI: $10.23880 / a b c a-16000145$

\section{Abstract}

The role of healthcare providers is crucial to the health and well-being of society and the relationship between the patient and the healthcare provider is of paramount importance. The trust put in this relationship benefits not only the health and well-being of the patient, but society as a whole. Undoubtedly, in their everyday activity healthcare providers are bound by a duty of care towards their patients. However, such duty is challenged in case of infectious diseases, giving rise to many ethical dilemmas. Is this duty absolute? Does it apply at all times? Would treating a patient with an infectious disease endanger healthcare provider's life or the life of others (his/her patients, family, colleagues, friends)? Would treating an infectious patient help the spread of the disease? Would refusal to treat jeopardize healthcare provider's career and future? Infectious diseases put a heavy social, economic and political burden on the state. This paper aims to examine the special role of the healthcare provider in cases of infectious diseases and the importance of their profession in the general well-being of society.

Keywords: Duty of Care; Healthcare Provider; Impact; Infectious Diseases; Rights

Abbreviations: ECG: Electrocardiogram; GPs: General Practitioners; WHO: World Health Organization; SARS: severe acute respiratory syndrome.

\section{Duty of Care}

Since the time of Hippocrates, in $5^{\text {th }}$ century BC, the role of a physician was to provide care, treatment and help for the sick. Hippocrates focused medical practice on the natural approach and treatment of diseases, highlighting the importance of understanding the patient's health, independence of mind, and the need for harmony between the individual, social and natural environment, as reflected in the Hippocratic Oath. The Hippocratic philosophy on health care provision focused on the holistic health care model, applying standards and ethical rules that are still valid today [1].

The principle of care in medical settings was later reinforced by Immanuel Kant in his work Groundwork for the Metaphysics of Morals [2]. According to Kant, people in general and physicians in particular have a universalizable moral obligation applicable to all people at all times, accessible and rationally acceptable to all. He classified duties as duty to oneself and duty to others. According to Kant, the majority of our moral duties, including a physician's duty to care for a patient, are duties of virtue. A person who decides to become a physician takes on the promise of using his or her abilities to the best advantage. Such a promise can be explicit (e.g., taking an oath) or implicit, but there is no denying its existence. This promise is a duty in itself, and the physician is morally bound to fulfill that duty. It is based on and oftentimes limited by the capabilities of a physician but it is not based on the patient's circumstances. The physician can take all necessary precautions to protect self and others from a disease but is duty-bound to treat the patient. If the physician chooses to refuse this duty, external conditions for example, peer pressure or a reminder of commitment to one's duty can be applied [3].

Nowadays, physician's duty of care is provided in Ethical and Deontological Codes (of the doctor, nurse, pharmacist, nutritionist, etc.). A duty of care exists once a doctor has seen a patient. A doctor also undertakes a duty of care 
once he has given telephone or other advice. For example, an on-call medical registrar who gives advice after looking at an electrocardiogram (ECG) undertakes a duty of care (to provide non-negligent advice) even if the registrar does not subsequently see the patient. Similarly, a surgical registrar who is telephoned by an emergency doctor about a minor rectal bleed and who advises that the patient can be discharged with outpatient follow-up has a legal duty of care to that patient. The undertaking of a duty of care is more complex for general practitioners (GPs) as they have a list of patients under their care who will not all be actively seeking advice. However, a GP does owe a general duty of care to those on their list, which is usually considered to become indisputable when a patient on the list seeks a consultation. In addition, GPs also have a legal duty to see any individual who has not seen a doctor for some time if that patient requests a review. The same principles apply to all healthcare professionals. A nurse has a duty of care to all those admitted to the part of the ward or department to which that nurse is allocated. Physiotherapists, dieticians and other professionals owe a duty of care to those they assess and treat. Any healthcare professional who goes to the aid of an ill or injured person when they are not employed to do so undertakes a Good Samaritan act [4].

In the everyday life there are situations which require a physician to refrain and not intervene. Such rule usually applies outside the professional settings p.ex. Stepping outside the hospital, must doctors stop by the roadside to assist a person in distress or respond to the dreaded call, "Is there a doctor on the plane?". If they do assist, they acquire a duty of care. The person becomes their patient. But should they help in the first place? [5].

Breach of the duty of care by the physician could result in negligence. The concept of 'negligence' was first introduced in the middle of 17-th century where negligence started to be seen as the basis for an independent wrong in itself, based on a person's failure to take reasonable care. Thus, every man ought to take reasonable care that he does not injure his neighbor. Therefore, wherever a man receives any hurt through the Default of another, though the same were not willful, yet if it be occasioned by negligence or folly, the law gives him an action to recover damages for the injury so sustained [6].

However, in order to establish negligence three elements must be proved: a duty of care, a breach of duty of care and causation. A duty of care is established where the injury caused by the other is reasonably foreseeable. 'A doctor will not be liable in negligence if he has acted in accordance with a practice accepted as proper by a responsible body of medical men skilled in that particular art' this means that a defendant will not be liable if he acts in a way that other equally qualified medical professionals would have done. 'A man is not negligent, if he is acting in accordance with such a practice, merely because there is a body of opinion that takes a contrary view'- this means that a medical professional will not be negligent even where there are medical professionals who would not have acted as the defendant did. Therefore, the defendant can avoid liability if there is a responsible body of medical men in the same field of medicine who confirm that the defendant's acts were appropriate in the circumstances [7].

In case of infectious diseases, a physician's duty of care, his professional rights and responsibilities, as well as ethical duties and obligations become somewhat less clear. In such cases the normal risk level of the working environment, the healthcare worker's specialty, the likely harm and benefits of treatment, and the competing obligations deriving from the worker's multiple roles will all influence the limits of the duty of care (Virulent Epidemics and Scope of Healthcare Workers' Duty of Care, 2006 [8]).

\section{The Impact of Infectious Diseases}

According to World Health Organization (WHO) infectious diseases are caused by pathogenic microorganisms, such as bacteria, viruses, parasites or fungi; the diseases can be spread, directly or indirectly, from one person to another. Infectious diseases can also be spread by animals to humans. Such infectious diseases are called Zoonotic $[9,10]$. Infectious diseases kill over 17 million people a year and are the world's leading cause of premature death. There are several ways that infectious diseases are spread:

- Through direct contact with a person who is sick. This includes kissing, touching, sneezing, coughing, and sexual contact. Pregnant mothers can also pass some germs along to their babies.

- Through indirect contact, when you touch something that has germs on it. For example, you could get germs if someone who is sick touched a door handle, and then you touch it.

- Through insect or animal bites.

- Through contaminated food, water, soil, or plants [11].

Since early civilizations infectious diseases have impacted humankind and societies, causing civilizationaltering consequences. The "Black Death" (1348-1350) killed $80 \%$ of those infected. At least 20 million people died, which was about two-thirds of the European population at the time. It slowed urbanization, industrial development and economic growth as people left cities and reverted to rural and agricultural life. The potato blight in 1845-1849 (known as The Great Famine), a fungal disease, caused the Irish potato famine, reducing the Irish population by $25 \%$ either through starvation or migration. During the Spanish flu pandemic in 
1918-1920, an estimated 50-100 million humans worldwide succumbed to the infection. When rinderpest spread to Eastern Africa in the nineteenth century, it caused massive death in livestock and the subsequent death by starvation of almost two-thirds of the East African Massai population [11]. In 2003, the world witnessed the spread of a novel and deadly virus, namely SARS CoV. The health care workers and hospital systems that bore the brunt of the SARS outbreak continue to struggle with the aftermath of the crisis. Health care workers both in clinical care and in public health were severely tested by SARS. Unprecedented demands were placed on their skills and expertise, and their personal commitment to their profession was severely tried. Many were exposed to serious risk of morbidity and mortality; indeed, approximately $30 \%$ of reported cases were among health care workers, some of whom died from the infection WHO, Consensus document on the epidemiology 2003 of severe acute respiratory syndrome (SARS). Today the world is going through the Covid-19 pandemic, with more than 34804348 cumulative cases confirmed and a death toll of 1030738 people and rising WHO, Coronavirus disease 2019 (COVID-19) Situation Report 04.10.2020.

While the primary cost of infectious diseases is loss of life, a secondary impact is economic: reduction in income and thus consumption [12]. The economic impact is not only individual (in time of sickness, epidemics or pandemics people spend more on medicines, vitamins, healthier food choices, etc.), but also affects the country. Infectious diseases decrease foreign investment and seriously effect on the economic growth of countries, especially poor ones. First, and perhaps most obviously, there are the costs to the health system, both public and private, of medical treatment of the infected and of outbreak control. A sizable outbreak can overwhelm the health system, limiting the capacity to deal with routine health issues and compounding the problem. Beyond shocks to the health sector, epidemics force both the ill and their caretakers to miss work or be less effective at their jobs, driving down and disrupting productivity. Fear of infection can result in social distancing or closed schools, enterprises, commercial establishments, transportation, and public services all of which disrupt economic and other socially valuable activity. Concern over the spread of even a relatively contained outbreak can also lead to decreased trade. For example, a ban imposed by the European Union on exports of British beef lasted 10years following identification of a mad cow disease outbreak in the United Kingdom, despite relatively low transmission to humans. Travel and tourism to regions affected by outbreaks declined. Some long-running epidemics, such as HIV and malaria, deter foreign direct investment as well [13].

Infectious diseases also impact countries' political systems as well as international security and foreign policy.
Infectious diseases have shaped societies, driven conflict and spawned the marginalization of infected individuals and communities throughout history WHO, Global Report for Research on Infectious Diseases of Poverty, 2012. In case of infectious diseases many countries take the necessary political measures to prevent the spread of the disease. Several individual freedoms are limited for the greater good of society. Budget funds are reallocated to buying medical equipment. Furthermore, foreign policy is used to coordinate response to infectious disease events and to advance population health around the world. Conversely, collaboration on infectious disease prevention, preparedness, and response is used strategically by nations to advance diplomacy and improve foreign relations [14].

Obviously, infectious diseases also a have social impact. During epidemics or pandemics limitations are put to many individual rights and freedoms. Freedom of movement is limited, right to education is limited (the majority of the classes are conducted through e-learning or homeschooling). The pursuit of happiness, as provided by the Declaration of the Independence of the United States of America, is also limited. Social gatherings, social activities, physical activities, etc. are limited to fight the spread of the disease. Furthermore, many are of the opinion that infectious diseases also differentiate between different economical class groups. For individuals with a high income is easier to get tested or get the vaccine that for those with a low income, thus displaying the inequality that exists between different groups of people, which leads to discrimination [15].

Infectious diseases have a significant impact not only on society and the overall physical and mental health of civilians, but they put a heavy burden also on healthcare providers, who have a duty of care towards the infected patients and an overall duty of care to ensure the overall health of the general population. These duties require them to take all necessary measures and follow recommended guidelines to ensure that their health and well-being is not affected due to treatment of infectious patients in order that failure to practice correctly does not result in occupational exposures or disease transmission. Thus, healthcare providers are the frontline that guarantees the economic, social and physical well-being of society during epidemics or pandemics and, in such situations they require particular attention and support, not only by domestic authorities but also by international institutions established to strengthen international defenses against infectious diseases.

\section{Duty of Care V. Infectious Diseases}

Infectious diseases test not only healthcare providers' knowledge, skills, rights, obligations and principles, but also the countries, their political systems and societies as a 
whole. Thus, in case of infectious diseases many dilemmas arise: Is a physician's duty of care absolute? Is a physician required to give his life in change for that of his/her patient? If a physician has to decide which patient lives or dies will he/she be breaching the duty of care towards the less cared patient?

The very nature of being a clinician entails a duty of beneficence to patients. Hence, morally, doctors have greater obligations to help patients than non-clinicians. The profession as a whole also has an implicit contract with society (which has usually subsidized medical training) to provide medical help in times of crisis. This raises several questions: what is an acceptable level of risk to the healthcare professional? When does the risk cease to be reasonable, and who should decide [16]?

Every nurse or doctor, by accepting a post, is usually aware of the perils of treating infected patients. The appearance of an exotic, highly virulent disease, however, challenges healthcare workers to question their interpretation of the duty of care, in particular, its limits. This challenge was apparent both in the HIV/AIDS epidemics of the 1980s in the United States and in the 2003 SARS outbreaks in Toronto, in which doctors and nurses refused to treat afflicted patients on the grounds that they presented too great a danger Virulent Epidemics and Scope of Healthcare Workers' Duty of Care [17]. During SARS outbreak serious concerns did surface about the extent to which health care providers would tolerate risks of infection. Some baulked at providing care to those infected with the unknown virus. In some circumstances, staffing became an issue in SARS wards and assessment centers. Failure to report for duty during the outbreak resulted in the permanent dismissal of some hospital staff. As a consequence, the risk that was faced during SARS was not distributed equitably, and those HCPs who volunteered to provide care faced the greatest exposure [18].

The job of a health care provider becomes even more difficult when dealing with infectious patients refusing treatment. While it is their duty to treat a consenting infectious patient, they are also obliged to treat a nonconsenting patient, thus limiting patient's individual autonomy, while at the same time putting their health at risk.

The answer with regard to the ratio between duty of care of healthcare providers and infectious diseases is mainly related to the means a state puts at the disposal of healthcare providers for the protection of their health. The primary and most important duty of care is that of the state to ensure that healthcare providers are protected and not exposed to risks of their health and safety. Thus, the better the protective equipment used by healthcare providers, the higher their duty of care towards the patients. Even though often it is hard to be certain which protective equipment will cover $100 \%$ the spread of the infection to the healthcare provider, in recent years the medical science has greatly improved, especially in economically developed countries. Equipment offered to healthcare providers has increasingly shown to protect them from infectious diseases, thus providing a safe working environment.

However, it must be stressed that while the governments have a duty of care towards healthcare providers and the healthcare providers a duty of care towards their patients, individuals also have a general duty of care towards other individuals, health care providers and society itself. They are the first who must take all necessary measures and comply with recommended norms to fight the spread of the disease, who should fully inform the healthcare providers on the symptoms of the disease and its effect upon them, and should follow the rules set out by their government to protect the population at large.

\section{Conclusion}

Health professionals play a central and crucial role in improving access and quality health care for the population. They provide essential services that promote health, prevent diseases and deliver health care services to individuals, families and communities based on the primary health care approach (WHO, World Health Organization) [19-22].

While health care providers' duty of care is of paramount importance to the health and well-being of society as a whole, there are certainly limitations to such duty. The application of such standard in medical settings must be taken in consideration in a case by case basis. Each case is different, the politics a country applies to fight the spread of the disease are different, the means at the disposal of health care providers also differ from country to country.

While the importance of such standard in healthcare should always be valued, we should also bear in mind the importance of the role and function of healthcare providers in society. Without their knowledge, skills and help in case of infectious diseases the entire word could be in danger. Thus, each time a healthcare provider's duty of care is questioned, his/her actions must be evaluated taking into consideration the circumstances of the case and the overall impact of healthcare provider's actions to his/her life and well-being vis à vis the well-being of the community.

\section{References}

1. Kleisiaris CF, Sfakianakis C, Papathanasiou IV (2014) Health care practices in ancient Greece: The Hippocratic 
ideal. J Med Ethics Hist Med 7: 6.

2. Kant I (2011) Groundwork of the Metaphysics of Morals: A German-English edition, CU Press.

3. Khan RI (2005) Clinicians' Duty to Care; A Kantian Analysis. Law \& Governance 9(4-5): 28.

4. Corfield L, Granne I, Latimer-Sayer W (2009) ABC of Medical Law. Blackwell 19-20.

5. Sokol DK (2012) Law, ethics, and the duty of care. BMJ 345.

6. Plunkett JC (2015) The historical foundations of the duty of care. Monash Univ Law Rev 41(3): 718-719.

7. Carr C (2015) Beginning Medical Law. Routledge Taylor \& Francis Group, pp: 186.

8. Sokol DK (2006) Virulent Epidemics and Scope of Healthcare Workers' Duty of Care. J Emerg Infect Dis 12(8): 1238-1241.

9. (2020) Infectious diseases. World Health Organization (WHO).

10. (2020) Infectious Diseases. Medline Plus.

11. Lindahl JF, Grace D (2015) The consequences of human actions on risks for infectious diseases: a review. Infect Ecol Epidemiol 5: 30048.

12. (2003) Consensus document on the epidemiology of severe acute respiratory syndrome (SARS). World Health
Organization (WHO), pp: 46.

13. (2020) Coronavirus disease (COVID-19) Weekly Epidemiological Update and Weekly Operational Update. World Health Organization (WHO).

14. Laxminarayan R, Anup Malani A (2011) Economics of Infectious Diseases. Oxford Handbook Online.

15. Bloom DE, Cadarette D, Sevilla JP (2018) Epidemics and Economics. International Monetary Fund 55(2): 46.

16. WHO (2020) Global Report for Research on Infectious Diseases of Poverty. For Research on Disease of poverty, pp: 168.

17. Katz R, Sorrell E, Standley C (2017) Infectious Disease as a Foreign Policy Threat. Oxford Research Encyclopedia of Politics.

18. (2016) Eliminating discrimination in health care: Stepping stone towards ending the AIDS epidemic. UNAIDS.

19. Simonds AK, Sokol DK (2009) Lives on the line? Ethics and practicalities of duty of care in pandemics and disasters. ERJ 34: 303-309.

20. Sokol DK (2006) Virulent Epidemics and Scope of Healthcare Workers' Duty of Care. Emerg Infect Dis 12(8): 1238-1241.

21. Ruderman C, Tracy CS, Bensimon CM, Bernstein M, Hawryluck L, et al. (2006) On pandemics and the duty to care: whose duty? who cares?. BMC Med Ethics 7(5). 